\title{
Kienböck Disease: Postoperative Radiographs at Long-Term Follow-Up
}

\author{
Roque H. Blanco, MD ${ }^{1}$ Fernando R. Blanco, MD ${ }^{1} \quad$ Fernando Cervigni, MD ${ }^{1}$ \\ ${ }^{1}$ Department of Hand Surgery, Clínica Universitaria Reina Fabiola, \\ Universidad Católica de Córdoba, Argentina \\ J Wrist Surg 2016;5:110-112.

\begin{abstract}
Address for correspondence Roque H. Blanco, MD, Department of Hand Surgery, Clínica Universitaria Reina Fabiola, Universidad Católica de Córdoba, Nicaragua 328, Villa Allende, Córdoba, CP 5105,
\end{abstract} \\ Argentina (e-mail: frblancos@gmail.com).
}
Abstract Keywords
- Kienböck disease
- radiographs
- lunate excision
- avascular necrosis

We present the radiographic results of four patients with Kienböck disease who had undergone a simple lunate excision at $26,30,35$, and 43 years after surgery.

Among the different surgical procedures proposed for the management of Kienböck disease, graded II to III according to Lichtman classification, lunate excision alone has always been controversial. Stahl ${ }^{1}$ and Therkelsen and Andersen ${ }^{2}$ early on reported poor results and condemned this procedure; conversely, Gillespie ${ }^{3}$ reported satisfactory results with this procedure.

In the last decades, few references about this procedure can be found. ${ }^{4-6}$

In November 1985, we published an article about a series of 11 patients submitted to lunate excision for stage III Kienböck disease according to Lichtman, with favorable outcome between 5 and 17 years postoperatively. ${ }^{7}$

Four of them were available for radiographic controls many years later.

\section{Radiographs}

Case 1. The patient was a 59-year-old housewife. Post-op period was 26 years. Rearrangement of the remnant carpus and congruity of the radiocarpal space are shown in posteroanterior and lateral views (-Fig. 1). Apparent synostosis between scaphoid and capitate is noted. No signs of degenerative changes are seen.

Case 2. The patient was a 56-year-old therapist. Post-op period was 30 years. - Fig. $\mathbf{2 A}$ indicates rearrangement of the remnant carpus and remodeling of the radiocarpal space. Impingement of the ulnar border of the radial surface into the

received

March 2, 2016

accepted after revision

March 13, 2016

published online

April 13, 2016

lunate space is noted. No degenerative changes are seen in this view (-Fig. 2B). In the oblique radiograph congruity between the radius and the palmar flexed scaphoid is shown. Flexion-extension angle was 65 degrees (-Fig. 2C).

Case 3. The patient was a 72-year-old physician. Post-op period was 35 years. Rearrangement of the remnant carpus is noted ( - Fig. 3A). Radial fossa of the scaphoid deepens. Impingement of the ulnar border of the radius and an osseous fragment into the lunate space is seen ( - Fig. 3B). - Fig. $3 C$ indicates obvious narrowing of the radiocarpal joint space. Active flexion-extension of the wrist ranged 75 degrees.

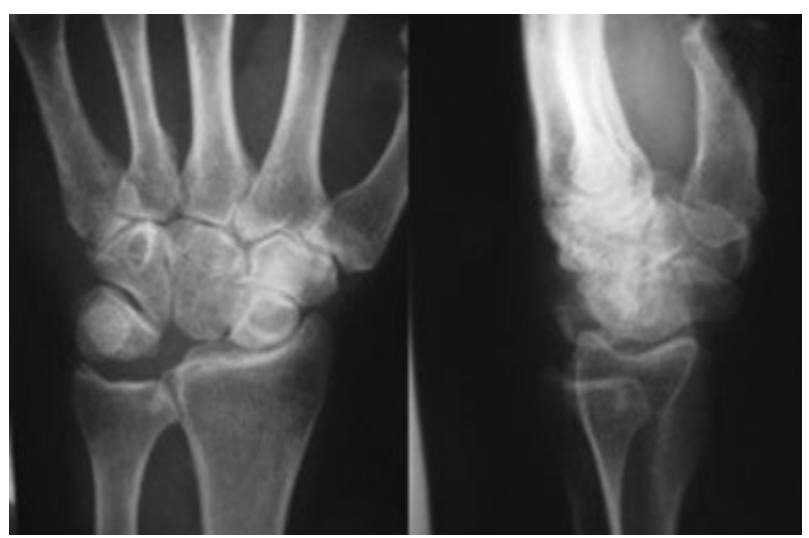

Fig. 1 Case 1.

Copyright $\odot 2016$ by Thieme Medical Publishers, Inc., 333 Seventh Avenue, New York, NY 10001, USA. Tel: +1(212) 584-4662.
DOI http://dx.doi.org/ 10.1055/s-0036-1582476. ISSN 2163-3916. 

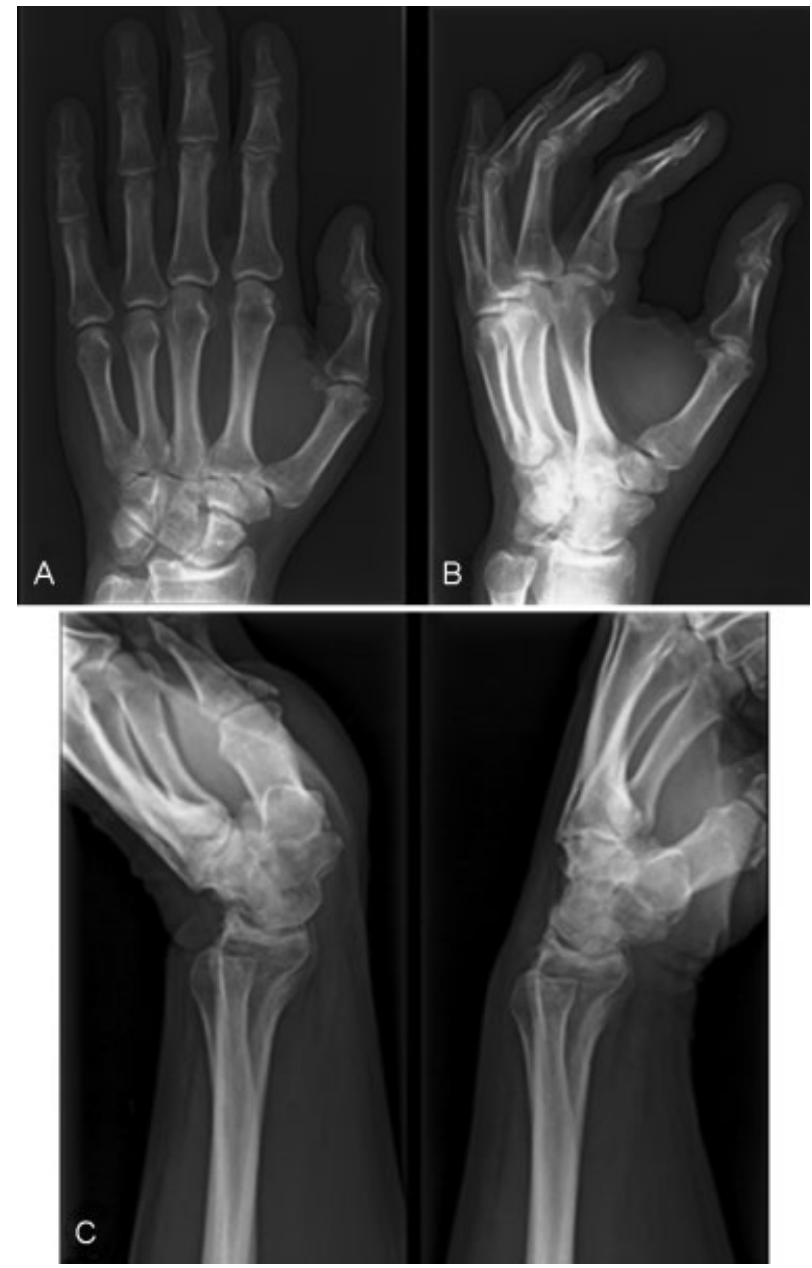

Fig. 2 Case 2.

Case 4 . The patient was a 75-year-old housewife. Post-op period was 43 years. Remodeling of the remnant carpal bones with apparent synostosis of the capitates to the scaphoid and hamate is shown. Note flattening of the capitate head (-Fig. 4A). Cyst is seen in the radius on posteroanterior and lateral views. Lateral radiograph shows moderate radiocarpal arthrosis (-Fig. 4B). Functional flexion-extension range of the wrist was 75 degrees (-Fig. $4 \mathbf{C}$ ).

\section{Discussion}

These case showed re-adaptation of the joint surface and rearrangement of the remnant carpal bones after long-term follow-up of excision of the lunate. ${ }^{4-7}$ This remodeling usually includes proximal migration of the capitate and triquetrum, and palmar flexion of the scaphoid with deepening of the radial fossa, among other changes. The range of movement of the wrist, including flexion-extension, can be considered as satisfactory at long-term follow-up.
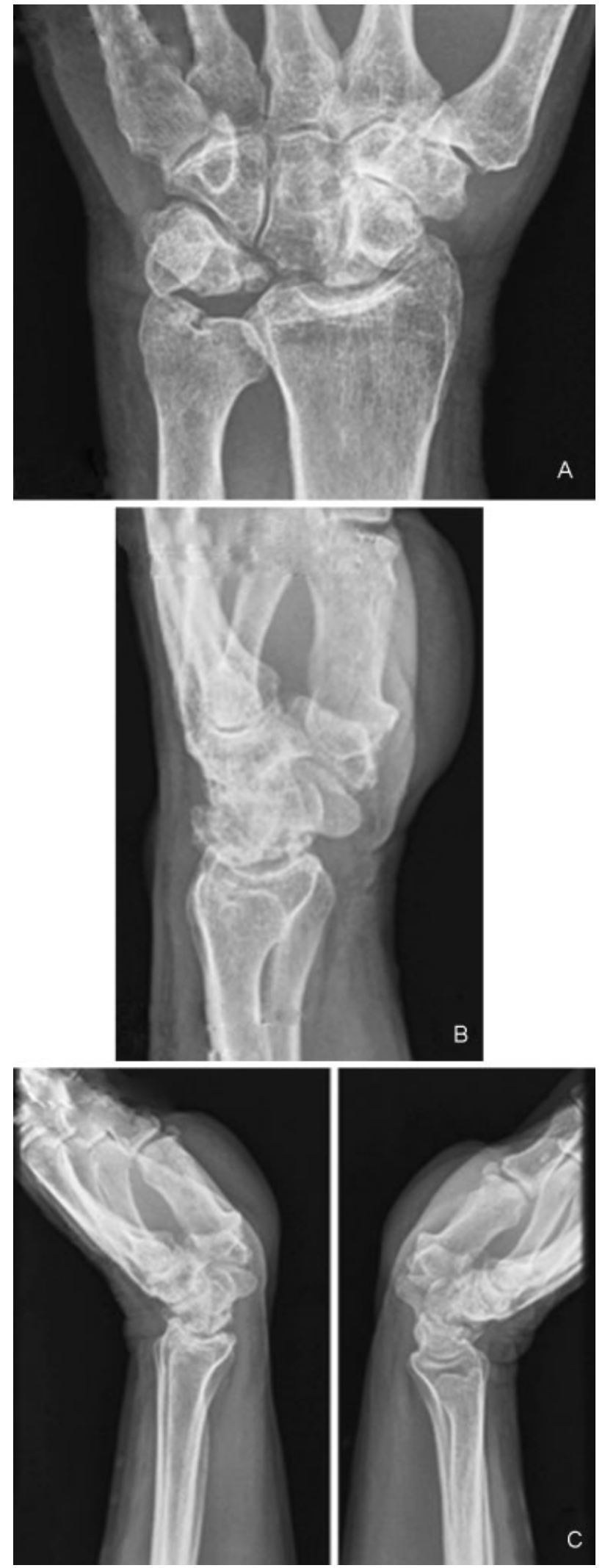

Fig. 3 Case 3. 

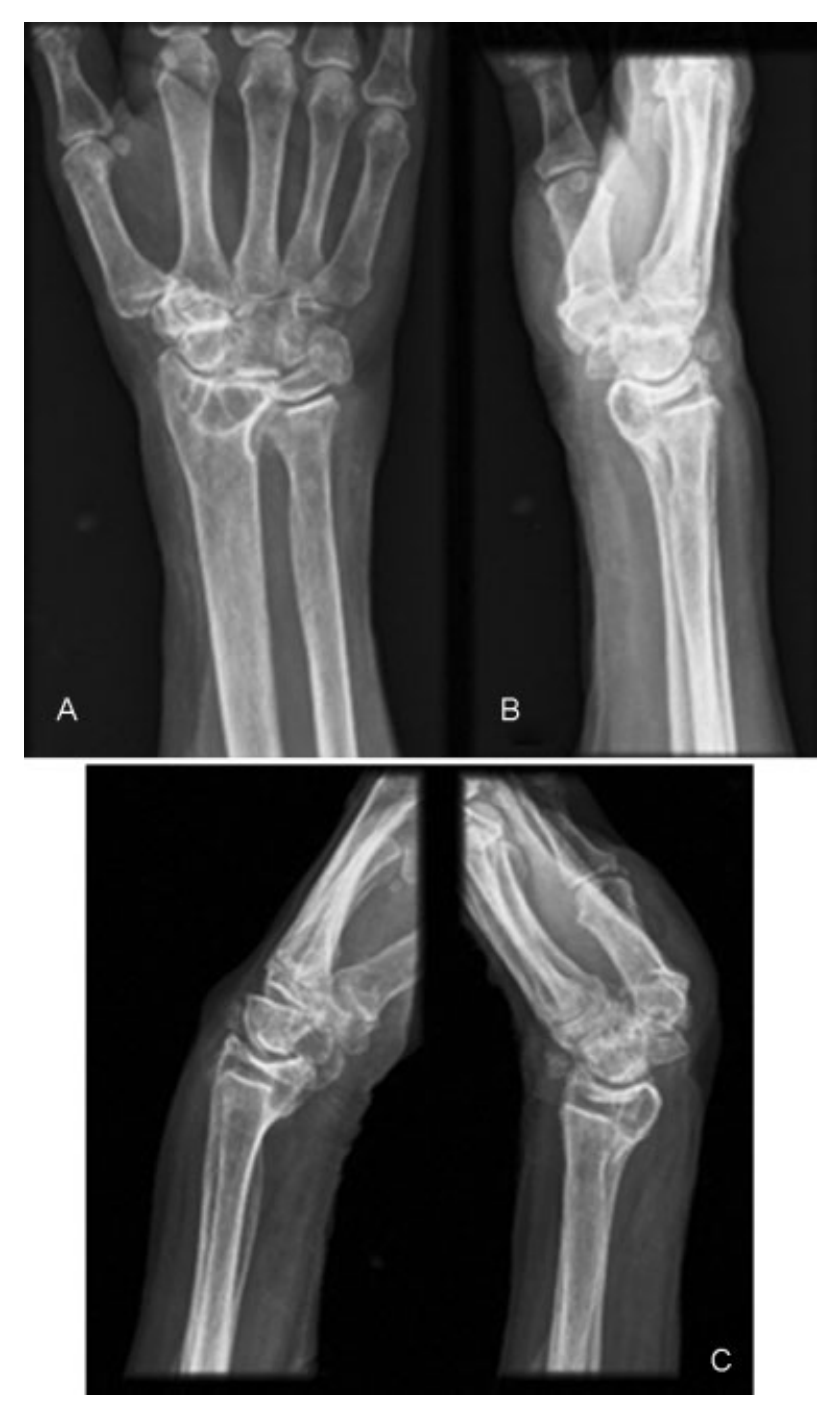

Fig. 4 Case 4.

\section{Conflict of Interest \\ None.}

\section{References}

1 Stahl F. On lunatomalacia (Kienböck's disease): a clinical and roentgenological study, especially on its pathogenesis and the late results of immobilization treatment. Acta Chir Scand 1947; 95(126):120-133

2 Therkelsen F, Andersen K. Lunatomalacia. Acta Chir Scand 1949; 97(6):503-526

3 Gillespie HS. Excision of the lunate bone in Kienböck's disease. J Bone Joint Surg [Br] 1961;43-B:245-249

4 Kawai H, Yamamoto K, Yamamoto T, Tada K, Kaga K. Excision of the lunate in Kienböck's disease. Results after long-term follow-up. J Bone Joint Surg Br 1988;70(2):287-292

5 Kawai H, Sedel L. Lunarectomie dans la maladie de Kienböck. Ann Chir Main 1990;9(4):271-275

6 Wheatley MJ, Finical SJ. A 32-year follow-up of lunate excision for Kienbock's disease: a case report and a review of results from excision and other treatment methods. Ann Plast Surg 1996;37(3): 322-325

7 Blanco RH. Excision of the lunate in Kienböck's disease: long-term results. J Hand Surg Am 1985;10(6, Pt 2):1008-1013 